[This document contains the author's accepted manuscript. For the publisher's version, see the link in the header of this document.]

\title{
The Swedish Model: Balancing Markets and Gifts in the Music Industry
}

\author{
Nancy K. Baym \\ University of Kansas \\ Correspondence concerning this paper should be addressed to: \\ Nancy Baym \\ Department of Communication Studies \\ University of Kansas \\ 1440 Jayhawk Blvd., Rm102 \\ Lawrence, KS 66045-7574 \\ Email: nbaym@ku.edu
}

\author{
Paper citation: \\ Baym, N. K. (2011). The Swedish Model: Balancing Markets and Gifts in the Music Industry. Popular \\ Communication, 14(1).
}

\begin{abstract}
:
The internet has destabilized media industries. This article uses the case of Swedish independent music labels, musicians, and fans to articulate one model for understanding the new roles each can take in this new context. Interviews, participant observation, and popular media coverage are used to show how labels and musicians in this scene loosely organize with fans to create a gift economy among themselves. Although they seek to earn money, they are not focused getting it from the audience. Instead, they engage the audience as equals with whom they can build a larger community that benefits them all. The article shows how they use giving songs away and engaging directly with audience members through the internet to pursue this goal. In contrast to discourses against file sharing, the analysis demonstrates how media producers may reconcile themselves to the participatory culture of the Internet.
\end{abstract}


The Swedish Model: Balancing Markets and Gifts in the Music Industry

In early 2008, seven independent Swedish labels formed a coalition they called “The Swedish Model." The first line posted on their website was a rejection of the music industry's focus on file sharing. "Hi music industry," they began, "hi all of you who on a daily basis must endure an unbalanced debate on distribution of music, and hi dear music fans." Later in their manifesto, they continued:

It hurts when old business models break. New models will however always take their place. Right now we're at the end of one epoch and in the beginning of another. The key to moving on is to let the old epoch die and the new germinate. That can only happen if one accepts the new conditions the internet has brought. And it is really time to try new ideas instead of clinging to the old.

This paper uses the exemplar of The Swedish Model to articulate "conditions the internet has brought" and "new ideas" that cast the internet as an opportunity for creative industries rather than threat. In his groundbreaking study of art as a gift Lewis Hyde (1983/2008), concluded that to live successful lives, artists living in market societies must find a way to reconcile gift exchange with market exchange. The internet has intensified the clash between market economies and gift economies in the music industry. The ease with which people can redistribute digital music files has savaged music's value as a commodity, yet in some ways increased its potential as a gift. The Swedish Model demonstrates how relations amongst media producers and consumers can be reoriented toward gifts without losing sight of the market. Through their practices, which include giving much of their music away and interacting directly with their audiences online, they invoke values of trust, egalitarianism, and community in place of the suspicion, hierarchy, and depersonalized markets that characterize the mainstream music industry's approach.

In 2008, I conducted qualitative interviews with Swedish label executives and musicians who are part of The Swedish Model, others who are not but who work in similar ways, and fans in several countries who actively promote Swedish independent 
music online and off. Those whom I identify have consented to have their name used. I supplement interview data with several years of participant-observation in the online Swedish independent music scene. I begin with a brief analysis of the "new conditions," addressing the recording industry's current crisis as its sources of power have been diminished by the internet and a more participatory culture has emerged. After a short introduction to the context of Swedish and independent music, I offer an analysis of The Swedish Model's "new ideas," explicating how file sharing and direct interaction with fans function as gifts that enable artists to build larger and increasingly international audiences, to form relationships, and to foster a larger and more meaningful community.

\section{New Conditions: Participatory Culture}

The history of music as a business is a microcosm of mass communication's past and a harbinger of mass media's future (Benkler, 2006; Briggs \& Burke, 2009). Once local and interpersonal, inherently relational, and shared with co-present others, the phonograph and the recording industry it spawned enabled music to become a centralized mass-produced commodity. Music became an object to be created at great expense, widely distributed and purchased at a set price, rather than an experience to be shared (Benkler, 2006). Thought there are countless recording labels, the contemporary recording industry is highly centralized, with 72 percent of the global market controlled by four firms (Universal Music Group, Sony Music Entertainment, Warner Music Group, EMI) (Wikström, 2009). Initially, digital technologies were kind to the recording industry. The conversion from vinyl records to compact discs led to a boom in the 1990s as people replaced vinyl with CDs. After the market's worldwide peak in 1998, however, the tide turned dramatically (Wikström, 2009). According to the research firm Forrester, total revenue from U.S. music sales and licensing was $\$ 14.6$ billion in 1999. Ten years later, it was down to $\$ 6.3$ billion, and it is projected to decline until 2014 (Goldman, 2010). Between 1999 and 2009, the four major labels reduced their workforce by 25 percent and their artist rosters by even more (Wikström, 2009).

This decline occurred in the context of a global financial crisis and the rise of other forms of entertainment such as gaming, but is indisputably due at least in part to 
industry failures in adapting to a well-networked audience able to do much more than it could before. This industry has faced extraordinary challenges coping with new conditions that favor "high connectivity and little control" (Wikström, 2009, p. 8). In contrast to records, CDs and other mass media, the internet "is the first modern communications medium that expands its reach by decentralizing the capital structure of production and distribution of information, culture, and knowledge" (Benkler, 2006, p. 30). For better or worse, after more than a century in which the recording industry has been driven almost entirely by selling the objects on which music was encoded, Forrester reports that a minority of American internet users, and only a slim majority of those who buy digital music, think digital music is worth paying for (Goldman, 2010). This decline in the financial value and sales of recorded music doesn't mean that there is any less music being created and distributed, nor that there are any fewer people listening to music. Music itself seems to be doing just fine. It's those seeking to earn a living or, worse yet, get rich, doing or enabling it whose revenue streams now need rechanneling.

Many media and internet scholars have written of the turn to "participatory culture" (e.g. Burgess \& Green, 2009; Dena, 2008; Deuze, 2006; Jenkins, 1992; Uricchio, 2007) in which media are increasingly created, distributed, and reworked by loose networks of interconnected peers. The concept of participation emphasizes the active nature of the audience (Ito et al., 2009; Jenkins, 1992) and undermines historical notions of clear distinctions between producers and audience. It draws attention to the communication amongst audience members and between audiences and media producers. "Rather than talking about media producers and consumers as occupying separate roles," writes Jenkins (2006, p. 3), "we might now see them as participants who interact with each other according to a new set of rules that none of us fully understands."

Audiences interact with one another and with producers through countless online venues. In the context of music, one of the most ubiquitous and certainly the most prominent form of participation is file sharing. Fans are motivated to make music listening a shared activity, a long-held value in music fan culture that shapes their practices of uploading and downloading music with others (Condry, 2004).

BigChampagneMedia Measurement, which tracks internet file sharing, reports that about 
90 percent of the music market is in unauthorized downloads, up exponentially since 2000 (Goldman, 2010).

There are also many more creative forms of participation. Spurred by easy access to recording technology and online distribution potentials, recent years have also seen an increase in amateur music production (Wikström, 2009). As described by Baym (2007), music fans also participate by writing mp3 blogs, online news sites, wikis, archives and booking live events. Less demanding ways to participate include logging listens, rating, tagging, and using "cloud" web services that license, store, and stream music such as Spotify, Pandora, and Last.fm (Baym \& Burnett, 2009). In this context, where "consumers are changing into users," business success "requires different leadership talents and foci" (Benkler, 2006, p. 126), a challenge to which the recording industry has thus far failed to rise. "There have been a lot of changes over the past 10 years," Joshua Friedlander, vice president of research at the Recording Industry Association of America (RIAA), said, "The industry is adapting to consumer's demands of how they listen to music, when and where, and we've had some growing pains in terms of monetizing those changes" (Goldman, 2010, n.p.).

Friedlander's use of the term "monetize," so common in music business parlance, may be indicative of the industry's troubles. For reasons that are deeply entrenched and not easily escaped, such as public corporations' fiscal accountability to stakeholders, major media companies generally approach their audiences as markets. This leads to viewing audiences as people who either pay or steal, as seen in a wide swath of industry trade group actions including installing DRM on purchases to limit their replicability, filing take-down notices against people who use or share music, suing people accused of file sharing, and seeking legislation to force Internet Service Providers to subsidize their industries or ban people accused of file sharing from the internet on their "third strike." In contrast, participatory culture operates more like a gift economy (Benkler, 2006, Hellekson, 2009; Jenkins, 2006). “Adapting to consumer's demands" may entail a shift away from seeing the audience as revenue streams toward seeing them as relational partners engaged in a shared enterprise. One could argue, as Wikström does (2009, p. 168), that although some file sharing is egregious and indefensible: 
social and creative music use is the normal way music fans use music in the new music economy. In other words, it is not the consumers who are out of line and should be brought back into the corral; it is the rights holders who need to rethink their terms of use.

The Swedish Model demonstrates an alternative participatory, gift-oriented view of labels' and audience's practices and responsibilities.

Gift economies (e.g. Hyde, 1983/2008; Mauss, 1950/2000) are often contrasted with market economies. Writing of the role of hospitality in the gift economy of Homeric Greece, Mifsud (2007, p. 98), explains that "things and people in a polis culture are related through distant, abstract mechanisms of power, rather than personal relations, and through technical proceduralism and utility, more so than through relational obligations, luxury, and honor." Blau (1964) compared economic and social exchange, distinguishing them along several dimensions. Where economic exchange entails specific obligations, a set rate of exchange and a set time frame for repayment, social exchange leaves all of this unspecified. Where economic exchange is based on legal principles and impersonal interaction, social exchange is based on trust, as the act of giving is presumed to create feelings of gratitude, obligation, and trust in the recipient that will eventually result in benefits to the giver. Where the value of what is exchanged in an economic transaction is independent of the provider, value in social exchange is tied to the giver. Exchanges may be reciprocal or circular (Hyde, 1983/2008). In reciprocal exchanges, people trade with one another. In circular exchanges, gifts are passed on to people other than the recipient, bringing more people into community as the gifts move amongst them. As gifts circulate in networks, social exchanges create communities. "A gift that cannot move," writes Hyde (1983/2008, p. 9), "loses its gift properties."

In practice, gift and market economies operate simultaneously and in complex, interdependent ways. "Social production of goods and services, both public and private, is ubiquitous, though unnoticed," writes Benkler (2006, p. 117). "It sometimes substitutes for, and sometimes complements, market and state production everywhere. It is, to be fanciful, the dark matter of our economic production universe.” People may switch 
between gift and market economies for dealing with in-groups and out-groups.

Indigenous cultures, faced with market/gift clashes, often adapt "an exchange-oriented code of conduct for dealing with outsiders while maintaining a gift oriented one for dealing with their own tribe"(Ippolito, 2000, p. 159). In parallel, contemporary fan communities create gift economies amongst themselves (Hellekson, 2009; Jenkins, 2006), even as they engage in (often conflicting) market economies with media producers.

The conjunction of art and commerce is famously fraught with conflict. When given as a gift, song carries meanings and values that are lost when it is bought and sold (Sarbanes, 2009). Hyde (1983/2008, p. 357) described gift exchange as "the primary commerce of art," writing that "unless the work is the realization of the artist's gift and unless we, the audience, can feel the gift it carries, there is no art." Once commodified, a gift loses its ability to foster community (Hyde, 1983/2008) and hence may become less rewarding for producers and consumers. For the middle and upper classes in Victorian England, for instance, the introduction of money into sports and entertainments reduced the pleasures they had provided (Benkler, 2006). For decades there have been few worse insults that can be bestowed upon a band than accusations of "selling out," or putting a profit incentive ahead of the perceived purity of artistic creation.

Since mid 1990s, the conjunction of the internet and market economies has also proven fraught. Until 1994, the internet was funded primarily by the United States' National Science Foundation and advertising and commerce were tightly restricted (Abbatte, 2000). The informal economy that arose online was mostly based on gifts, as people used Usenet groups, bulletin boards, mailing lists, chat, and other forums to share resources in public so that all would benefit (Barbrook, 1999; Rheingold, 1993). Increasingly, the internet has been "colonized by a culture based on accumulating" (Ippolito, 2000, p. 159), as large profit-driven corporations have become dominant forces (consider, for example, Google and Facebook). Terranova (2000, p. 36) drew attention to the importance of the internet's original and continuing gift economy in providing a "labor force" for the "larger digital economy" and described the digital economy's reliance on free labor as indicative of "the reproduction of the labor force in late 
capitalism as a whole." In a paper focusing on music fans' attitudes toward providing free labor, Baym and Burnett (2009) showed that fans active in promoting bands have tacit and explicit strategies for balancing the tension between the effort they expend and the rewards they receive. The potential for corporate exploitation of "user-generated" gift economies is ever present.

In short, then, the internet has brought about many new conditions for the music and other media industries. They have lost their status as sole distributors of their core commodity and have not yet been able to regroup. In place of a powerbase built on content control is a decentralized, participatory structure in which the content has been fiscally devalued, but still widely circulated and socially valued. This can be understood, at least in part, as a clash between an economy built on market values and one built on participatory values.

\section{Swedish and Independent Music}

This paper focuses on independent labels and artists in Sweden and the fans throughout the world who promote that scene online and off. Though a small market, Sweden is known for its music culture and has been unusually successful in exporting its music internationally (Wikström, 2009). This has early roots in the 1840 s when P.T. Barnum brought opera singer Jenny Lind, "the Swedish Nightingale" to America, making her the first international Swedish star and arguably the world's first musical celebrity. As many music publications and news sources such as The New York Times have noted in recent years, in addition to housing production studios and producers that create international pop hits performed by artists such as Beyonce and Britney Spears, Sweden has a thriving indie scene. It includes countless unsigned artists as well as those represented by dozens of small independent labels such as Labrador Records (Stockholm and Malmö), Hybris (Stockholm and Malmö), Adrian Recordings (Malmö), Songs I Wish I Had Written (Malmö), Gravitation (Göteborg), West Side Fabrication (Skellefteå), and NonStop (Stockholm). As Baym (2007) described, "Swedish indie music spans many genres including death metal and its sweet and wimpy opposite "twee," electronica, 
progressive rock, hip hop, jazz, Americana, punk, and indie-scene starwalt genre "indiepop."'"

In contrast to major labels, the indie music business is better situated to respond to the participatory turn, in part because it has historically had a strong ethos of resistance to corporate control (Kruse, 2003; Fonarow, 2006). In her ethnographic account of the British indie music scene, Fonarow (2006) argues that indie can be seen as a means of distribution, a genre, an ethos, a style, and an aesthetic. Rather than denoting a monolithic group in static agreement, indie is located in the contentious discourse amongst artists, labels, promoters, journalists, fans and others engaged in praxis around each of these issues. Despite the variation within the community she describes, Fonarow identifies a shared ethos based on positioning the "indie community" in opposition to the mainstream, "combating the dominant hegemony of modern urban life" (2006, p. 67). While "mainstream evokes all that is enormous, distant and unspecialized," "indie connotes small, personal, and immediate" (2006, p. 63). In what she calls "the indie cosmology," the goal for listeners is "to find communion with the sacred quintessence of music. Differences in musical practices are interpreted through a moral frame, producing an aesthetic system based on moral values" (2006, p. 28). She describes indie moral values as in line with Puritanical ideology, advocating "simplicity in songs, modesty in adornment, modesty in consumption, and a particular type of physical discipline to acquire a look that suggests an aversion to worldly pleasures" (2006, p. 50). It is within this morally-loaded context that many indie labels and performers are able to interpret and practice file sharing and other internet practices as tools for culture building.

In contrast to the British indie scene Fonarow (2006) described, the Swedish indie scene is technologically astute and not generally working class. Swedish indie musicians often have strong musical educations and university degrees. At least one label executive interviewed for this project has a Ph.D. in Philosophy. Like artists the world over, however, they often earn their income outside of music. Hyde (1983/2008) describes this as converting market wealth to gift wealth by serving as their own patrons. This is true of those running independent labels as well as those making music (and there is often much overlap between the two). Says Mattias Lövkvist of the label Hybris: 
Most [people in the Swedish indie music scene] have day jobs, but that has always been the case. Maybe for short period they can live on the music but most have jobs. Maybe after a while they can write for others, for film, TV commercials, they can find an angle to work in music field. But there are more people earning money now from music than before in Sweden.

Musician Gustaf Kjellvander of The Fine Arts Showcase lives on the earnings from his music, "but I'm poor," he says, "It's hard to make money off music but to get by isn't that hard, if you're not picky about living a no-frills life." Martin Thörnkvist, who spearheaded The Swedish Model and runs the label Songs I Wish I Had Written, explains that he "didn't start Songs I Wish to become rich, which makes it much easier for us to try new things. There's no shareholders in the US that will be angry if we do the wrong thing." At the time I interviewed him, he worked part time at an advertising firm and made some additional money as a public speaker discussing the ideas behind The Swedish Model at music industry events. Independents, as these three indicate, are motivated by "the joy of independence and the pleasure of creating something new (intrinsic motivation)," while the majors are "primarily driven forward by the need to fulfill the next financial plan (extrinsic motivation)" (Wikström, 2009, p. 30). While urging against romanticizing starving artists, Hyde (1983/2008, p. 364) cautions us not to conflate financial poverty with a lack of wealth: "When the song of one's self is coming all of a piece, page after page, an attic room and chamber pot do not insult the soul."

\section{New Ideas}

\section{Recasting File Sharing}

Internal motivation and satisfaction with modest finances shape these independents' attitudes toward file sharing. As Wikström (2009) explains, there tend to be two responses to file sharing. The first, represented by trade organizations such as the Recording Industry Association of America (RIAA), the European equivalent International Federation of the Phonographic Industry (IFPI), and the Motion Picture Association of America (MPAA), among others, is that file sharing is illegal, directly replaces sales, and should be stopped. The second perspective holds that: 
music firms actually benefit from the audience's increased access to musical content. The increased accessibility has facilitated audience action (cf. the audience-media engine) and more people will be able to discover music and broaden their musical experience, which is beneficial to the entire music industry. Based on that logic, the appropriate action by the music industry would be to support the uncontrolled circulation of copyrighted material on the Internet, rather than to try to wipe it out. (Wikström, 2009, p. 150)

That the Swedes discussed here should cleave to the second perspective is not surprising. Until recently, Sweden's technological infrastructure and slow copyright legislation made it a nurturing home for file sharing and copyright infringement (Wikström, 2009). Since 2009 , legislative changes, the initial conviction of the four founders of once-top file sharing site The Pirate Bay, and the domestic success of the legal music streaming site Spotify (founded by Swedes) seem to have cooled that welcome. The link between technological libertarians such as the men behind The Pirate Bay and The Swedish Model is direct. Thörnkvist and one of the executives from the music label Hybris, which participates in The Swedish Model, share an office space with one of the Pirate Bay founders, Peter Sunde Kolmisoppi, as well as other friends and collaborators. Thörnkvist and Sunde Kolmisoppi often give talks together.

For the people I interviewed, file sharing is an indisputable positive. It is the tool through which culture is being built. Trying to stop or even debate it is seen as a damaging waste of time. Says Thörnkvist:

We got really tired of polarized debate about file sharing. This isn't how we look at it so lets just say how we look at it. Which is common sense, we're positive about the future, we try to focus on the music and helping each other out, especially abroad, and try to be a positive side of the business because every one's really tired about major labels hunting their fans and stuff like that. Right from beginning we got really good press and people liked what we did so it's nothing revolutionary. We're trying to be positive and optimistic. 
In an open letter to the press on their blog, Hybris announced they were not doing any more interviews until journalists were ready to frame their stories in terms of culture rather than file sharing:

This issue is about our whole culture. You know, that itsy bitsy thing that separates us from being ants. [...] In 1999 we downloaded music in big fashion for the first time. Since then it's been an endless stream [...] the way culture is built today, is through filesharing. There are loads of things filesharing has had an impact on. Irreversible impact. Like how one builds ones identity. [...] Downloading of music, movies, games and programs is only one side of the story as well. On the other hand there is communities, blogs, websites with loads of information, free information of high and low (THE lowest) quality everywhere, all the time and it's increasing by the minute. It goes hand in hand with the downloading of music, movies, programs and games. It's stressful, highpaced, superficial and at times very rewarding. It's a world of culture under ongoing change at a level so basic that it probably will have replaced the old system completely in a couple of years. 4 years, counting from last Thursday, is our guess. The change is exactly like the change when Copernicus told people that the universe doesn't spin around the world. It's exactly like that. (Hybris blog, 2008, January 31)

The overriding benefit of file sharing that the labels and musicians interviewed expressed was that it enabled them to get their music heard. As one musician put it:

It's kind of cool that we live in a time where you can hear about a band and then type it in and listen to it the same day. When I was younger you'd hear about some band, ask the record shop, and they'd say 'no but we could order some.' It's a very different scene.

Enabling people to type in their bands' names then listen is valued more than control over distribution. It's thus common practice for Swedish independent labels and artists to give at least some of their music away in the form of mp3 files placed on their websites and elsewhere or by uploading it to streaming services. Mattias Lövkvist of Hybris attributes much of his label's success to their strategy to "put out mp3 songs from the start for 
everyone to download. That made a big impact in the beginning." Johan Angergård, who runs the label Labrador and plays in three of its bands (Club 8, The Acid House Kings, and The Legends), concurs in describing his ideal label page. "I'm not asking for much," he says, "a page where you can download MP3s from every band and I'm happy."

Labrador gives away all of their singles as downloads on their site and uploads annual samplers to The Pirate Bay as part of a strategy to make music "very easy to find." This is not seen as a conflict with sales revenue. Says Angergård:

If someone reads about an artist on Labrador in a physical paper and want to listen to the music it should be very easy to find it. If they find their way to Labrador.se they can download MP3s from all bands. If they're on Last.fm they can hear every album in full there. Etc. If you're a small label you have nothing to lose by spreading your music. If you're U2, everyone knows your music and streaming and MP3s cuts into sales, but I very much doubt that's the case with [our bands] Sambassadeur or The Mary Onettes."

Thörnkvist explains how he promotes the music released by Songs I Wish I Had Written and other labels associated with The Swedish Model:

Being everywhere. You can find Songs I Wish or The Swedish Model in as many places as we have time to update from Muxtape to Pirate Bay. I'm seeding all the The Swedish Model records on Pirate Bay. For me it's just great to have a little bit of power over which quality it is seeding in. For example Moto Boy, there's only one torrent and I know that it's good quality.

Musicians and labels trust that if people redistribute their music, they will gain a larger audience that can bring more benefits than they would otherwise get:

If people like music they talk about it, they tell loved ones, they burn the records for people they know and that's a big part of spreading music. It's so much easier now because you can send a whole record as a file in 2 seconds too, so I definitely think it helps me. It definitely helps me. (Kjellvander) 
Every single listener, you never know who will get to know about your music through which person. Those 10 people could be the most important people in his career, you never know. (Thörnkvist)

With Internet you get bands known, and that creates a market for them, both for live shows and selling albums. (Angergård)

From the fans' point of view, this commitment to making music easy to find is integral to their positive perception of a band or label and, in the case of the fans I interviewed, their willingness and ability to cover them on the sites for which they write. Johannes Schill is a Swede who runs an archive site called Hello!Surprise! where he provides links to over 500 independent Swedish pop bands, MP3s they have made available, and more than 40 independent labels. The labels that he includes "are in one way or another good at reaching their fans. They're giving away free MP3s.” Avi Roig, who runs an American webzine called It's A Trap! dedicated to Scandinavian music describes "a good web presence" as including "lots of free samples." Roig and other active online fans hold up several of the labels mentioned already and others as exemplars:

Hybris is easily one of the best in that they update regularly, give away a ton of music and videos and also maintain a blog that covers much more than just their own music. Labrador is pretty good about giving music away too (as well as streaming it on Last.fm) and so are Nomethod and Adrian. (Roig)

"Hybris is quite good at showcasing its artists through its site," says another active fan, "with lots of music and video clips and free downloads."

When labels give their music away without expecting, let alone demanding, direct reciprocation, it functions as a gift, and thus as a "symbol of relation" (Lawler \& Yoon, 1996, p. 91). As Bergquist and Ljungberg (2001, p. 313) describe in their analysis of the open source community as a gift economy, gifts like this:

are often not given to anyone in particular. They are made public (on webpages) and thereby made available to anyone who cares to make use of them. An application or 
some information does not really become a gift until someone finds it and makes use of it. If a giver manages to get attention, people will turn the things offered into gifts, which means that a relationship is created between the giver and the user.

As fans pass these songs around, their acts of giving serve as evaluations of quality. This evaluative component of gift giving is something classic theories of gift economies "haven't accounted for" (Bergquist \& Ljungberg, 2001, p. 306), but is strikingly important in this scene where cutting through the din of all the music available and gaining audience attention is so challenging (see Baym \& Burnett, 2009). In an interview with the blog Muzzle of Bees (2008, February 10), Mathias Stromberg from The Bell, a Swedish band who have been relatively successful internationally, elaborated the importance of online fans as evaluators of musical releases:

Being Swedish, I believe in a regulated society, that we need certain tastemakers, or editors, between sender and receiver. This is where (the good) blogs and online mags/forums come in handy. There is simply too much out there to take in so we need to help each other. Something that I think will create a better world in maybe ten, twenty years time, a better climate to create and activate thousands of creative minds that never would have a voice if it wasn't for the internet. There won't be much I'll like but people will be happier.

At the base of the concept of gift economy is the notion that gifts must ultimately be recirculated. Within this scene, musicians and artists give at least some of their songs away. When fans then pass it on, they recirculate the gifts, building audience, community, and endowing the music with credibility.

\section{Internationalizing Audiences}

Giving music away online also allows bands and labels to develop international audiences that the complexities of territorial distribution deals and limited financial means render otherwise difficult. For Swedish bands, the placelessness of the internet has offered sizable audiences in the United States, the United Kingdom, Asia, Brazil, and other countries. As Kibby (2010, p. 240) wrote, "information about what once were 
called 'local artists' is now much more readily available on a global basis and musicians are in a position to collect audiences across global barriers."

Labrador Records estimates that at least two third of their recordings are sold outside Sweden. Hybris explicitly pursued international markets from the start:

Hybris started only 3 years ago, immediately with a tone on our homepage communicating that we're a global label. We immediately began to contact webshops and distributors in other countries. Swedish record sales have decreased a lot. We are one of the labels that have succeeded best. But we sell a lot more records abroad than before. Our sales are about 50/50 Swedish/international from our home page, but our international sales are more with our distributors. We sell to Taiwan, Japan.

Kjellvander describes how he and others have found new international audiences:

The internet helps so much, especially MySpace. People are listening to the Fine Arts Showcase in India and Thailand and Indonesia and stuff. That would never have happened 10-15 years ago. On other hand, you look at The Nomads and they had a pretty big following in America. Bands like the Lovekevins that don't sell more than 200-300 records in Sweden, I've read rave reviews of them internationally. [...] I wouldn't be doing this interview [with an American] if it weren't for the internet. Nobody in Indonesia would listen to The Fine Arts Showcase.

Once international audiences have been found online, bands and labels also benefit from how much easier it becomes to book shows abroad:

[Touring is] so easy now. You can have your eye on a Swedish artist even if you're sitting in Taiwan or the UK. There's also like new networks starting to develop German fans that like Swedish music and book Swedish music, another guy in the UK is doing something like that, and in Spain. (Lövkvist)

a lot of people get in contact to book gigs. But also, [the internet] makes it a lot easier to find booking agencies in different countries. I actually can't understand how it worked before Internet. People who contact us and want to arrange gigs are usually fans. Quite often fans doing gigs professionally, but still fans. (Angergård) 
When fans provide this effort to bring artists to their countries, they may offer hospitality that goes far beyond the market duties of booking a show, continuing a cycle of gift exchange. Stacey Shackford, who booked a Swedish music club in Glasgow for several years, for instance, noted that she and her partner "house the bands at my apartment, and feed them while they are here." Musicians may also view performing before international audiences as a gift that validates their work and transforms the relationship between artist and fan in a way the internet makes possible but cannot directly provide. Angergård tells me:

I think what's changed my relationship with fans the most is things like the fact that we've started playing live with Club 8. Especially when we're in Asia it's a very special feeling. Being there I can tell that our music actually makes a difference to people. And it's easier to tell when you meet them compared to receiving an email.

Even if the email is ever so positive.

Thus, although the scene is grounded quite literally in Sweden, the artists and bands, together with the fans, are able to build global communities. "The internet has made the world at your doorstep," says Kjellvander, "I don't think sense of community should be bound to locality." "What I think is really fascinating about this bands and fans and the internet," says Nick Levine, the "guy in the UK" who booked Swedish bands in London through his club Tack!Tack!Tack!, “is that there are bands who are not very massive anywhere in the world but who have these tribes who can be traced through sites like Last.fm and MySpace all over the world."

\section{Direct Interaction}

Those I interviewed also use the internet to engage in direct interaction with their fans, a practice they view as providing them with numerous professional and personal rewards. Says Thörnkvist:

The internet made it possible to have a relationship with fans. Before you could send a letter, but nowadays you can talk to the artists directly on MySpace and stuff like 
that. Before there weren't any relationships but the name. Now its actually communication for the first time.

Angergård agrees, "It's a lot easier for people to contact you and so you communicate a lot more with your fans." MySpace, which was the most-used site at the time of the interviews (2008), and similar sites offer bands a forum in which they can control their images in contrast to media coverage and fan-driven discourse. Independent Swedish bands usually create and maintain their own MySpace pages and, as one highly active fan puts it, "that's the main form of communication." Swedish bands frequently note that fans seem more likely to contact them through MySpace than through email. "Since I got into MySpace," says Jonas Färm of Starlet, "interaction between me and people who like the music has increased by hundreds and hundreds of percent."

The fans think it is particularly important that the band itself manages the MySpace page. Levine discusses how an independent band he had been active in (voluntarily) promoting has an inadequate MySpace account now that they have signed with a label: "someone at the label is handling [their] MySpace account and they don't seem to doing a good job of it. They're not using it creatively or imaginatively." MySpace can thus be used poorly. It also has other drawbacks. Schill, the archivist, laments, "I understand how much a site like MySpace must have made things easier for the artists/groups. It's too bad [...] MySpace's 96kbps streams are annoying if you ask me." Furthermore, Schill complains that he cannot link to MySpace streams on Hello!Surprise!, limiting his ability to recirculate the songs.

Although the interviewed artists generally have a presence on MySpace, there are other ways artists and labels engage in direct communication with their audiences, including their own websites, Last.fm and other social network sites including Facebook, and blogs. Given the decline of MySpace since the interviews were conducted, these alternative means have become increasingly important. Most use multiple means of accessing fans directly. As a typical musician says, "I use my MySpace site, my ordinary web site, in some ways I use my Last.fm site, I use the [band's] e-mail address." 
At the least, most artists and all labels maintain a website, which is often a moreinformational alternative to their MySpace page. The Cardigans, a particularly successful Swedish band, provide continuous information through their website, but also feature an "Ask The Band" section where fans can submit questions that their bass player faithfully answers. Jens Lekman, one of Sweden's most successful independent artists, has no MySpace account. For a time, when one clicked the "MySpace" link on his own website, it loaded a page at his own domain which resembled a blank MySpace template. In small letters, its only content read "fill in the blanks." However, he is regarded as an online exemplar because, as one fan said, "Lekman keeps a personal online blog, which is very popular, and he often makes new music available through exclusive free downloads on his site."

Blogs may be ongoing or tied to special events such as tours or recording sessions. Adrian Recording artist eMiL Jensen, for instance, writes a blog in which he frequently has one-on-one interaction with fans in the comments. He also created a shortterm blog to chronicle his bicycle-powered European tour. Roig lists several:

artists that are good about blogging regularly: Marit Bergman, Jonna Lee as well as Sara Culler and David Fridlund (David \& the Citizens). Tiger Lou has a new studio blog that will be promising if he keeps it up. Scraps of Tape is good about keeping a tour diary when they travel. Irene and Björn Kleinhenz also do well with providing regular updates.

In addition to their own websites, labels often use mailing lists to communicate with their fans. Says Angergård, Labrador's “mailing list seem to work quite well. There's probably, and naturally, a lot of people with good taste in music on that one. You sign up at the top to the right at [our website]." Labels also create YouTube channels featuring their artists videos. Thörnkvist doesn't just moderate his artist Moto Boy’s YouTube page, he keeps an eye on videos fans post and combines and recirculates them:

For every concert he's playing there's loads of YouTube, which is really good because then you have a place to collect what the fans are doing for your artist. I downloaded the best ones from every song and put them into a Moto Boy YouTube 
concert which is 45 minutes of YouTube clips from every concert. But it's not on YouTube cuz its too long, it's on Vimeo.

Some labels, such as Hybris, Adrian Recordings, and collectively The Swedish Model, blog as well.

Although the openness bands exhibit through these media has many advantages, it can mean giving up the mythos of the artists, and perhaps some of their appeal:

Some bands are like that, they always respond to everybody on MySpace. That's a good thing, it's more natural in a way. It's both good and bad. Some artists are better if you don't know so much about them. 10 years ago you could fantasize about how an artist was. Maybe you'd only read one well-written interview a year. (Lövkvist)

The nature and implications of this direct contact are different for bands and labels. Bands are expected to be accessible, and most directly reap the benefits of such personal interaction. Labels can maintain more distance:

it seems as if I, personally, have more directly communicated with someone if it's a fan of one of my bands. Emails about Labrador is more like "I love Labrador, you're the best label" (and that is wonderful to hear!) while emails to a band like Club 8 can be more like "This song saved my life." (Angergård)

Hybris is everywhere: Last.fm, MySpace, but we don't really talk to fans. I think it's a good thing to have distance, so they can build a myth. (Lövkvist).

In contrast to artist blogs, label blogs tend to be more promotional and reflective on the industry than personal.

Direct interaction between bands and fans can function as a gift in itself for both. Lawler and Yoon (1996, p. 90) have argued that "consummated exchanges give actors an "emotional buzz"." Fans who receive messages from artists, especially when they are addressed specifically to them, are liable to experience that message as a gift, enhancing their perceived social ties to the artist. By the same token, the artist who is told that his song saved someone's life or who receives continuous queries from people displaying 
interest in and care for his music, is also receiving a gift that transcends money. Regular interactions can make a relationship "an expressive object, valuable in its own right, because mild, positive emotions are produced by successful exchanges, and parties in these exchanges attribute this emotion in part to their relationship" (Lawler \& Yoon, 1996, p. 89).

Through this process of sharing, interaction and informal gift exchange, the relationships between artists and fans become more egalitarian than hierarchical. This Swedish model positions all participants as members of a shared culture in which all roles are open to all. Says Kjellvander:

If someone wants to ask me something they can ask me. That's amazing. That's great. There shouldn't be a dividing line. I don't believe that there should be. It's breaking down the barriers of the inaccessibility of the artist, which is good. It makes people realize it's something they can do themselves. It's important to remember that people who play music are just people. The internet helps that, it's not this huge iconic book of characters, rock stars. Personally I think the rock star thing is boring and played out. Its good it's just people playing folk music. Music by the people for the people.

Sometimes, those I interviewed resisted the very term "fan" in describing their listeners. In an email interview, one musician wrote that:

the barrier is down, or a lot of it, thanks to MySpace, Last.fm and other sites. The hierarchy is flattened, me and my "fans," and the same with artists I like and adore, are in a way on the same level.

His use of quotation marks around "fan" appeared again in my chat interview with Angergård, who wrote that they "email quite a bit with the "fans" (I'm having a hard time use the word "fans"... I'm thinking of screaming Madonna fans here...)." When pressed for a better word, he replied, "Well, "fans" might be the right word. It's just that the pictures I see in my head are hysterical teenagers at a crappy show and not someone sitting in front of their home stereo loving the The Mary Onettes album." These equal, social relationships between musicians and fans can develop into genuine friendships, particularly when the ties built online move offline. "We enjoy building relationships 
with fans," says the frontman for the band Hell on Wheels, "especially meeting them in real life... we've made some real friends that way."

\section{Building Community}

In sum, bands and artists in this scene are using file sharing sites, social network sites, websites, blogs, mailing lists, and other online media to give their music to and communicate directly with their audience. This direct access allows artists and labels to get their music heard, to build their audience domestically and internationally, to expand their touring possibilities, to keep their fans informed, and to have interactions and build relationships that are inherently rewarding on their own terms. Although they do not use the word "gifts," at the heart of these processes is their perception of the internet as a site for gift exchange. Instead of resisting the music audience's desire to share and talk about music with one another, they provide them with the resources to make that happen, trusting that the exchanges that ensue as those gifts recirculate will ultimately, if indirectly, work for their benefit. Instead of seeing audiences as revenue sources waiting to be correctly monetized, they view them as allies in a cause that has many ways to break even or at least turn an adequate profit. "You don't have to get the money from the customer any more," said Thörnkvist, "you can do it in many different ways." One label executive explains:

I'm giving up on selling cds, but we're making cds and trying to get them on elsewhere, we can't make money from selling them. I'm trying to figure out different ways to earn money and get artists to be professional musicians: Setting up clubs, trying to get people who have money to pay for the music. Like companies pay for using your music because then you can rip some fuckers with money off, like sponsorships. I have nothing against that. If the sponsorship thing is good and you feel like both parties are winning on it. Companies realize they can't get their logo on everything.

The purpose of gift economies is to build social ties. "The theory of the gift," writes Mifsud (2007, p. 89), "is a theory of human solidarity." The Swedish Model cares 
about the market economy, and seeks to participate profitably within it. But they are more concerned with building a larger community that will benefit everyone. In place of centralized control and profit, this model is based on all participants - labels, bands and fans - using the internet to unite and expand a culture of what Angergård refers to as "like-minded people that share a common love." As Lövkvist explains:

Listeners who are into our kind of music, they are more music fans than the general listener. That kind of person has increased in number over last 5-6 years. In Stockholm now there are tons of clubs that play our kind of music. It's $100 \%$ file sharing and the internet that we have to thank. All people involved in indie music have known that if we could only get exposure we'd be huge. The majors had marketing and budgets, but the internet made it easy for the independents.

Instead of marketing, these labels choose to trust potential audience's taste. Says Angergård, "hopefully, MP3s, Myspace, Internet, blogs and all that changes things so that we more and more have to put our trust in people's good taste in music (and our way of presenting our music I suppose) rather than big muscle marketing." In his youth, Angergård reflects, "I felt [my favorite] labels were little universes of their own. That's how I want Labrador to be." The internet has offered a way for him, and others, to make and expand their "little universes" to include others across the globe who share their tastes and values. "A lot of our fans share common values with the whole file sharing," says Lövkvist, "we share a common value -- shared music taste, discontent with the dominant major labels."

Although they express dissatisfaction with the major labels, these independents believe that the major labels are important, and should be included in the new musical revival they see coming. They greet their failings with more sadness than glee, simply because they too are fans. As Thörnkvist put it:

For like 10 years I've been thinking that the major labels can do whatever they want, they can sue fans, they're just messing it up for themselves but it's good for me because the fans will like me even more. But then I realized what the future would be like - I think it'd be great if it looked like streaming models, all the music in one 
place, kind of free, and then I realized those services I want to be part of won't be good enough without majors on there.

Daniel Johansson, a Swedish music strategist and academic associated with the Swedish Model describes it this way on his blog (2009):

Most pirate supporters seems to forget that most of the music they love has come to life because of record labels. They seem to forget that during many years, record labels have been the creative center for the global music industry, finding, developing, recording and publishing the music that we all love. Record labels are not bad. They have just been a little confused.

\section{Conclusion}

The Swedish Model is just one manifestation of the broader phenomenon of media producers finding ways to come to terms with the participatory culture of the internet and the networked powers of their audiences. "From the perspective of diagnosing what is happening to our social and economic structure," says Benkler (2006, p. 84), "the fact that the files traded on these networks were mostly music in the first few years of this technology's implementation is little more than a distraction." This is about much more than The Swedish Model, the independent music sector, or even the music industries. It is about the new relationships audiences and producers must negotiate in a technological era that favors decentralization and gift exchange over control and sales.

Jennings (2007, p. 7) has argued that "labels and managers should focus on the 'whole fan' and concentrate on their lifetime value as committed advocates, which may mean indulging the odd misdemeanour in return for having someone who will evangelise and recruit more fans on your behalf for years to come." The Swedish Model takes this approach, not just ignoring but actively encouraging "odd misdemeanours" in expectation that the gifts they offer - in the form of their songs and their communication - will circulate back to bring them just reward. It is easy to be too utopian about this, and some of the people I've interviewed could be accused (and sometimes happily claim the title) of being idealists. There are still serious problems, even in this model, foremost among 
them, the fact that no one is sure how to make money in music anymore. Musicians, labels, and other entertainment producers are testing a huge variety of models. These include Radiohead's allowing people to download their album from their own website and pay as much (or as little) as they like, Trent Reznor's many creative experiments with promoting, giving away, and selling exclusive editions of Nine Inch Nails albums, Jill Sobule's solicitation of fan-funding prior to recording, and many more. A large secondary industry of services built to facilitate artist-fan interaction, organization, and financing has emerged. No one knows what will and won't work for which kinds of media in the long run.

The Swedish Model draws attention to the role of affect in shaping new giftoriented business models. Gift exchange creates feeling. In a gift economy, "there will be an ongoing and generalized indebtedness, gratitude, expectation, memory, sentiment - in short, lively social feeling" (Mifsud 2007, p. 84) that in turn creates "cultural intimacy" and "cultural memory" (Mifsud, 2007, p. 94). The internet "speeds up" the accretion of these acts and feelings into "a collective entity" (Terranova, 2000, p. 42). In putting the focus on creativity, quality, gift exchange, and trust, The Swedish Model demonstrates how the culture industries might reorient in order to facilitate "lively social feeling" in ways that benefits all. Perhaps this idealistic sentiment is best conveyed by Fårm, who ended his interview with this plea:

Let's stop the exploitation of music. Let's stop thinking of music as export business merchandise products. Let's stop the people who try hard to infiltrate music scene just because they see money potential in it. That goes for politicians as well for the music corporations. Let's socialize, that's the most important thing that we can use the Internet for.

Jenkins (2006) wrote that no one fully understands the rules anymore. In The Swedish Model we see a way of negotiating these rules that celebrates the potentials of participatory culture and models how many more decentralized, participatory media companies will likely act in the future. What distinguishes the successful companies from the failures may be how proactively they pursue these participatory new visions rather than clinging to models based on conditions that no longer exist. 


\section{References}

Abbate, J. (2000) Inventing the Internet. MIT Press, Cambridge, MA.

Baym, N. K. (2007). The new shape of online community: The example of Swedish independent music fandom. First Monday, 12(8) http://firstmonday.org/issues/issue12_8/baym/index.html

Baym, N. K. \& Burnett, R. (2009) Amateur experts: International fan labour in Swedish independent music. International Journal of Cultural Studies 12(5), 433-449.

Barbrook, R. (1998). The High-Tech Gift Economy. First Monday, 3(12) http://www.uic.edu/htbin/cgiwrap/bin/ojs/index.php/fm/article/view/631/552

Benkler, Y. (2006). The Wealth of Networks: How Social Production Transforms Markets and Freedom. New Haven and London: Yale.

Bergquist, M. \& Ljungberg, J. (2001). The power of gifts: organizing social relationships in open source communities. Journal of Information Systems, 11, 305-320.

Blau, P. (1964). Exchange and Power in Social Life. New York: Wiley.

Burgess, J. \& Green, J. (2009). YouTube: Online video and participatory culture. Cambridge, UK: Polity

Condry, I. (2004). Cultures of music piracy: An ethnographic comparison of the US and Japan. International Journal of Cultural Studies 7(3): 343-363.

Dena, C. (2008). Emerging participatory culture practices: Player-created tiers in alternate reality. Convergence (14)41. doi: 10.1177/1354856507084418

Deuze, M. (2006). Participation, remediation, bricolage: Considering principal components of a digital culture. The Information Society (22)2, 63-75.

Fonarow, W. (2006). Empire of Dirt. Wesleyan University Press. 
Goldman, D. (2010, February 3). Music's lost decade: sales cut in half.

CNNMoney.com,

http://money.cnn.com/2010/02/02/news/companies/napster_music_industry/?hpt=P1

Hellekson, K. (2009). A fannish field of value: online fan gift culture. Cinema Journal, 48(4): 113-118.

Hyde, L. (1983/2005). The gift: Imagination and the erotic life of property. New York: Random House.

IFPI (2009). Recorded Music Sales 2008. The International Federation of the Phonographic Industry, London.

Ippolito, J. (2001). Whatever happened to the gift economy? Leonardo, 34(2): $159-160$

Jenkins, H. (1992). Textual poachers: Television fans and participatory cultures. London: Routledge.

Jenkins, H. (2006). Convergence culture: Where new and old media collide. New York: New York University Press.

Jennings, D. (2007, 7 February). Getting fans in on the act. MusicAlly Report,185, 6-7.

Johansson, D. (2009, December 14) The Swedish music industry in graphs report. http://www.danieljohansson.se/post/The-Swedish-Music-Industry-in-Graphs-Report.aspx [Accessed February 1, 2010]

Kibby, M (2010) The Gendered Practice of Fandom Online, R. Lind (Ed.) Race/Gender/Media: Considering Diversity Across Audiences, Content and Producers 2nd edition Chicago, AB-Longman: 237 - 244

Kruse, H. (2003). Site and sound: Understanding independent music scenes. New York: Peter Lang. 
Lawler, E. J. \& Yoon, J. (1996). Commitment in exchange relations: Test of a theory of relational ochesion. American sociological review, 61(1), 89-108.

Mauss, M. (2000/1950). The Gift: The Form and Reason of Exchange in Archaic Societies. Trans. W. D. Hall. New York: W. W. Norton.

Mifsud, M. (2007). On rhetoric as gift/giving. Philosophy and rhetoric, 40(1), 89-

Sarbanes, J. (2009). The Shaker "gift" economy: Charisma, aesthetic practice and utopian communalism. Utopian studies, 20(1), 121-139.

Terranova, T. (2000). Free Labor: Producing Culture in the Digital Economy. Social Text 18:2, 33-58.

Uricchio, W. (2007). Moving beyond the artifact: lessons from participatory culture. In Y. de Lusenet \& V. Wintermans, (Eds.) Preserving the Digital Heritage. The Hague: Netherlands National Commission for UNESCO and the European Commission on Preservation and Access, Amsterdam, 15-25

Wikström, P. (2009). The music industry: Music in the cloud. Cambridge, UK: Polity. 